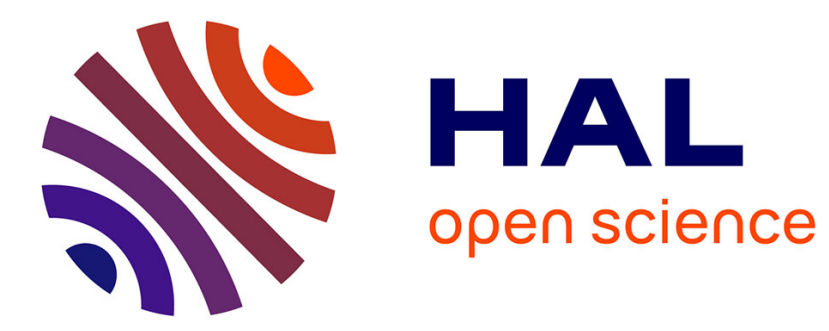

\title{
On the accuracy of the CO 2 surface fluxes to be estimated from the GOSAT observations
}

Frederic Chevallier, Shamil Maksyutov, Philippe Bousquet, Francois-Marie

Breon, Ryu Saito, Yukio Yoshida, Tatsuya Yokota

\section{- To cite this version:}

Frederic Chevallier, Shamil Maksyutov, Philippe Bousquet, Francois-Marie Breon, Ryu Saito, et al.. On the accuracy of the CO 2 surface fluxes to be estimated from the GOSAT observations. Geophysical Research Letters, 2009, 36 (19), 10.1029/2009GL040108 • hal-02946549

\author{
HAL Id: hal-02946549 \\ https://hal.science/hal-02946549
}

Submitted on 7 Oct 2020

HAL is a multi-disciplinary open access archive for the deposit and dissemination of scientific research documents, whether they are published or not. The documents may come from teaching and research institutions in France or abroad, or from public or private research centers.
L'archive ouverte pluridisciplinaire HAL, est destinée au dépôt et à la diffusion de documents scientifiques de niveau recherche, publiés ou non, émanant des établissements d'enseignement et de recherche français ou étrangers, des laboratoires publics ou privés. 


\title{
On the accuracy of the $\mathrm{CO}_{2}$ surface fluxes to be estimated from the GOSAT observations
}

\author{
Frédéric Chevallier, ${ }^{1}$ Shamil Maksyutov, ${ }^{2}$ Philippe Bousquet, ${ }^{1}$ François-Marie Bréon, ${ }^{1}$ \\ Ryu Saito, ${ }^{2}$ Yukio Yoshida, ${ }^{2}$ and Tatsuya Yokota $^{2}$ \\ Received 16 July 2009; revised 27 August 2009; accepted 14 September 2009; published 14 October 2009.
}

[1] This paper quantifies the value added by the Greenhouse gases Observing SATellite (GOSAT) to numerical models of the global carbon cycle for the estimation of $\mathrm{CO}_{2}$ surface fluxes. The metric used here is the theoretical uncertainty reduction, defined as one minus the ratio of the posterior flux uncertainty to the prior ones. Our results indicate that GOSAT should significantly improve our knowledge of the $\mathrm{CO}_{2}$ surface fluxes over terrestrial vegetated areas, even at the scale of a week and of a few hundred kilometres. Over ocean and in spite of the GOSAT sun-glint-pointing capability, large improvements are seen only when the fluxes are aggregated both over ocean basins and over a year. Citation: Chevallier, F., S. Maksyutov, P. Bousquet, F.-M. Bréon, R. Saito, Y. Yoshida, and T. Yokota (2009), On the accuracy of the $\mathrm{CO}_{2}$ surface fluxes to be estimated from the GOSAT observations, Geophys. Res. Lett., 36, L19807, doi:10.1029/2009GL040108.

\section{Introduction}

[2] The long-lived $\mathrm{CO}_{2}$ molecule has been accumulating in the atmosphere since the start of the industrial revolution, and has reached levels that are unprecedented in at least 800,000 years [Lüthi et al., 2008]. The accumulation of this greenhouse gas is the main driver for climate change and motivates ambitious monitoring programmes, like the Cooperative Air Sampling Network, managed by the NOAA Earth Systems Research Laboratory, or, recently, the Integrated Carbon Observation System (ICOS) in Europe. Besides, $\mathrm{CO}_{2}$ is a long-lived gas in the atmosphere so that the background concentration is large compared to the gradients generated by local fluxes. As a direct consequence, the monitoring of such gradients requires very demanding relative accuracies. This may explain why the monitoring of $\mathrm{CO}_{2}$ from space is much more challenging than for shorter-lived species, such as carbon monoxide or aerosols. A prominent application of $\mathrm{CO}_{2}$ measurements from space would be the estimation of its surface sources and sinks [Rayner and O'Brien, 2001], in the context of the studies performed with the sparse network of surface stations (e.g., Gurney et al., 2002). A first $\mathrm{CO}_{2}$-dedicated platform has been placed into orbit on 23 January 2009. This satellite, the Japanese Greenhouse gases Observing SATellite (GOSAT, also known as IBUKI [Yokota et al., 2004]), carries a Fourier-transform spectrometer that col-

\footnotetext{
${ }^{1}$ Laboratoire des Sciences du Climat et de l'Environnement, CEA, UVSQ, IPSL, CNRS, Gif-sur-Yvette, France.

${ }^{2}$ National Institute for Environmental Studies, Tsukuba, Japan.

Copyright 2009 by the American Geophysical Union. 0094-8276/09/2009GL040108
}

lects information about $\mathrm{CO}_{2}$ and $\mathrm{CH}_{4}$. The GOSAT observations are being processed to generate a suite of products that will successively include column averaged dry air mole fraction of $\mathrm{CO}_{2}$ (hereafter $\mathrm{X}_{\mathrm{CO} 2}$ ) and $\mathrm{CO}_{2}$ surface fluxes. The instrument is expected to be operated during five years.

[3] This paper evaluates the information that GOSAT will provide about surface fluxes, and is an extension of the simplified assessment of the GOSAT observation made by Maksyutov et al. [2008]. It follows the strategy of Chevallier [2007] and Chevallier et al. [2007] who studied the products of the parallel US project, the Orbiting Carbon Observatory (OCO) [Crisp et al., 2004] which was unfortunately lost during launch in February 2009. This strategy relies on an ensemble of observation system simulation experiments (OSSEs) with a variational flux inversion scheme.

[4] The GOSAT data are described in the next section. The evaluation method is described in Section 3. The results are presented in Section 4. Section 5 concludes the paper.

\section{GOSAT Measurements}

[5] GOSAT orbits around the globe with a polar sunsynchronous trajectory. The descending orbits cross the Equator at about 13:00 local time. Relative to the Earth, the orbit pattern repeats every 3 days. The main GOSAT flight instruments is the Thermal And Near infrared Sensor for carbon Observation-Fourier Transform Spectrometer (TANSO-FTS). From the infrared spectrum, this Fouriertransform spectrometer will provide information about the concentrations of $\mathrm{CO}_{2}$ in the upper-troposphere, similarly to what the Atmospheric Infrared Sounder (AIRS) has been doing since 2002 and with limited interest for flux estimation [Chevallier et al., 2005a]. In the near infrared, TANSOFTS will look at sunlight reflected from the surface and will inform about the whole $\mathrm{CO}_{2}$ column, with some contribution from the boundary layer concentration, which is critical for flux monitoring.

[6] At nadir, the field of view of TANSO-FTS is a circular footprint with a diameter of about $10 \mathrm{~km}$. A cross-track scanner extends the measurements between the orbit tracks. Over the ocean, TANSO-FTS will point to the glint spot in order to compensate for the low reflectivity of the ocean in other viewing directions. The latitudinal range of sun-glint observations varies with the declination of the sun for the actual operation of TANSO-FTS. Since the retrieval of $\mathrm{X}_{\mathrm{CO} 2}$ will be hampered by clouds and aerosols, GOSAT carries a cloud and aerosol imager that facilitates the interpretation of the TANSO-FTS measurements.

[7] Figure 1 shows the result of a simulation of the sounding coverage that could be achieved for three days 


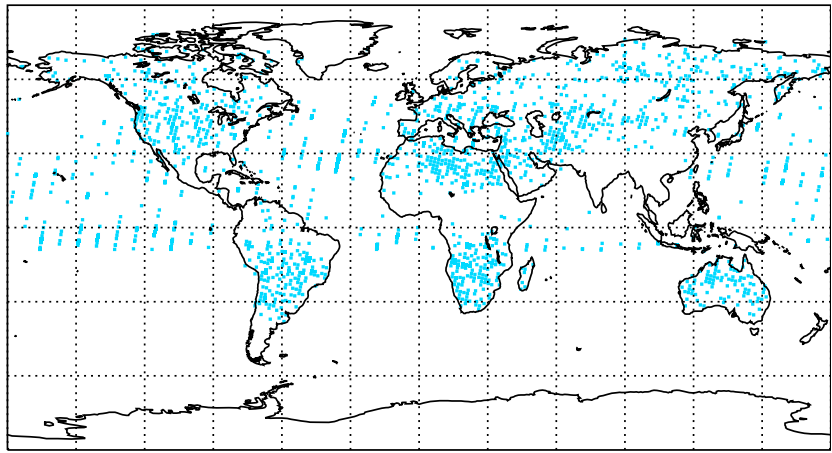

Figure 1. Simulated density of the GOSAT $\mathrm{X}_{\mathrm{CO} 2}$ retrievals for 3 days of July.

of a month of July. The data density varies with the abovementioned elements: solar radiation, pointing mode and cloud cover. To assess the impact of cloud cover, the distribution of the clear-sky occurrence was taken from the global database of Eguchi and Yokota [2008].

[8] $\mathrm{X}_{\mathrm{CO} 2}$ is retrieved by the usual optimal estimation method [Yokota et al., 2008]. The theory allows the estimation of the retrieval uncertainty and of its vertical resolution, described by the averaging kernel. This column averaging kernel (not shown) is similar to that of the OCO retrievals, as estimated by Connor et al. [2008, Figure 2]: it is fairly constant from the surface to about $4 \mathrm{~km}$, and then decreases towards the upper atmosphere. The similarity with OCO is not surprising since the two instruments use the same spectral bands to infer $\mathrm{X}_{\mathrm{CO} 2}$. The uncertainty of the individual GOSAT soundings is parameterized here with a two-step method, based on numerical simulations of the GOSAT retrieval algorithm. First, the signal-to-noise ratio of the measured spectra is computed from the surface albedo $a$ and from the solar zenith angle $\theta_{z}$ by the following relationship based on the designed performance of TANSOFTS, e.g., $\mathrm{SNR}=300$ when albedo $=0.3$ and solar zenith angle $\theta_{z}=30$ deg.:

$$
S N R=350 \frac{a}{0.3} \cos \theta_{z}
$$

Data are left out when $a^{*} \cos (z)$ is larger than 0.3 because of saturation effects, as well as for $S N R$ lower than 100. For the sun-glint tracking mode, over the ocean, the glint reflectance replaces the albedo in equation (1). It is parameterized from the model of Bréon and Henriot [2006, equation (6)].

[9] The standard deviation of the individual $\mathrm{X}_{\mathrm{CO} 2}$ sounding errors, SSE, in ppm, is then obtained from:

$$
S S E^{2}=\frac{300^{2}}{S N R}+1.2^{2}
$$

The first term in the right side of equation (2) accounts for measurement noise, smoothing error, and interference error component, while the second term represents the overall random contribution of aerosols to the retrieval noise [Ota et al., 2008]. The computed errors vary between 1.2 and $3.2 \mathrm{ppm}$. These figures are larger than those given by Connor et al. [2008] for OCO that were mostly below $1 \mathrm{ppm}$.

[10] The transport model error and the representativeness of the observations with respect to the transport model grid are represented here by a $1 \mathrm{ppm}$ standard deviation. This rough estimate is quadratically added to the individual observation errors, raising them to values between 1.6 and $3.4 \mathrm{ppm}$. Although these errors are most likely correlated in space and in time to some extent, such correlations are not implemented here for lack of knowledge.

[11] The GOSAT soundings are averaged at the horizontal resolution of our transport model (a $3.75^{\circ} \times 2.5^{\circ}$ longitudelatitude grid) at the orbit level. These averaged observations should have a smaller uncertainty than the individual ones, but to an extent that depends on the (unknown) error correlations. The reduction of the error by averaging is not taken into account.

\section{Method}

[12] $\mathrm{CO}_{2}$ surface fluxes are estimated from $\mathrm{X}_{\mathrm{CO} 2}$ retrievals by an inversion scheme that combines them with some prior information about the fluxes within a Bayesian framework. GOSAT will provide thousands of soundings every day. Weeks of individual data have to be processed simultaneously by the inversion system because of the long life of the $\mathrm{CO}_{2}$ molecule. The state vector is also quite large. It includes a large number of individual fluxes to be estimated (here daytime and night-time 8-day-mean fluxes on a $3.75^{\circ} \times 2.5^{\circ}$ longitude-latitude grid throughout the temporal window of the inversion) and some constraint on the concentrations at the start of the inversion window (here 2D scaling factors on the total columns). We make use of the variational inversion scheme of Chevallier et al. [2005b] that can handle large-dimension inference problems. The method relies on the iterative minimization of a Bayesian cost function. 30 iterations with the conjugate gradient algorithm of Fisher and Courtier [1995] are enough to reach convergence with the GOSAT soundings. The operator that links the state vector and the observation space in the inversion scheme is the general circulation model of the Laboratoire de Météorologie Dynamique (LMDZ) [Hourdin et al., 2006], nudged to ECMWF winds and used in an offline mode (transport mass fluxes are read from a frozen archive rather than computed on-line). Tracer transport is simulated on a $3.75^{\circ} \times 2.5^{\circ}$ (longitude-latitude) horizontal grid and with 19 layers between the surface and the top of the atmosphere.

[13] The error statistics of the prior fluxes are a key component of the inversion system and they have been modelled by a multivariate Gaussian distribution. They are illustrated in Figure 2a. Over land, the parameters of the distribution are inspired by the comparison between in situ flux measurements and the outputs of a biosphere model that was reported by Chevallier et al. [2006]: (i) temporal correlations decay exponentially with a length of one month but night-time errors are assumed to be uncorrelated with daytime errors, (ii) spatial correlations decay exponentially with a length of $500 \mathrm{~km}$ (i.e. about the East-West size of the transport model grid at the Equator), (iii) standard deviations are set proportional to the heterotrophic respiration fluxes of a simulation of the Organizing Carbon and Hydrology in Dynamic EcosystEms (ORCHIDEE) [Krinner et al., 2005] (the scaling factor, deduced from the data of Chevallier et al. [2006], is 2.5), with a cap at $6 \mathrm{gC} \mathrm{m}^{-2}$ day $^{-1}$. Over a full year, the statistical uncertainty for all land 

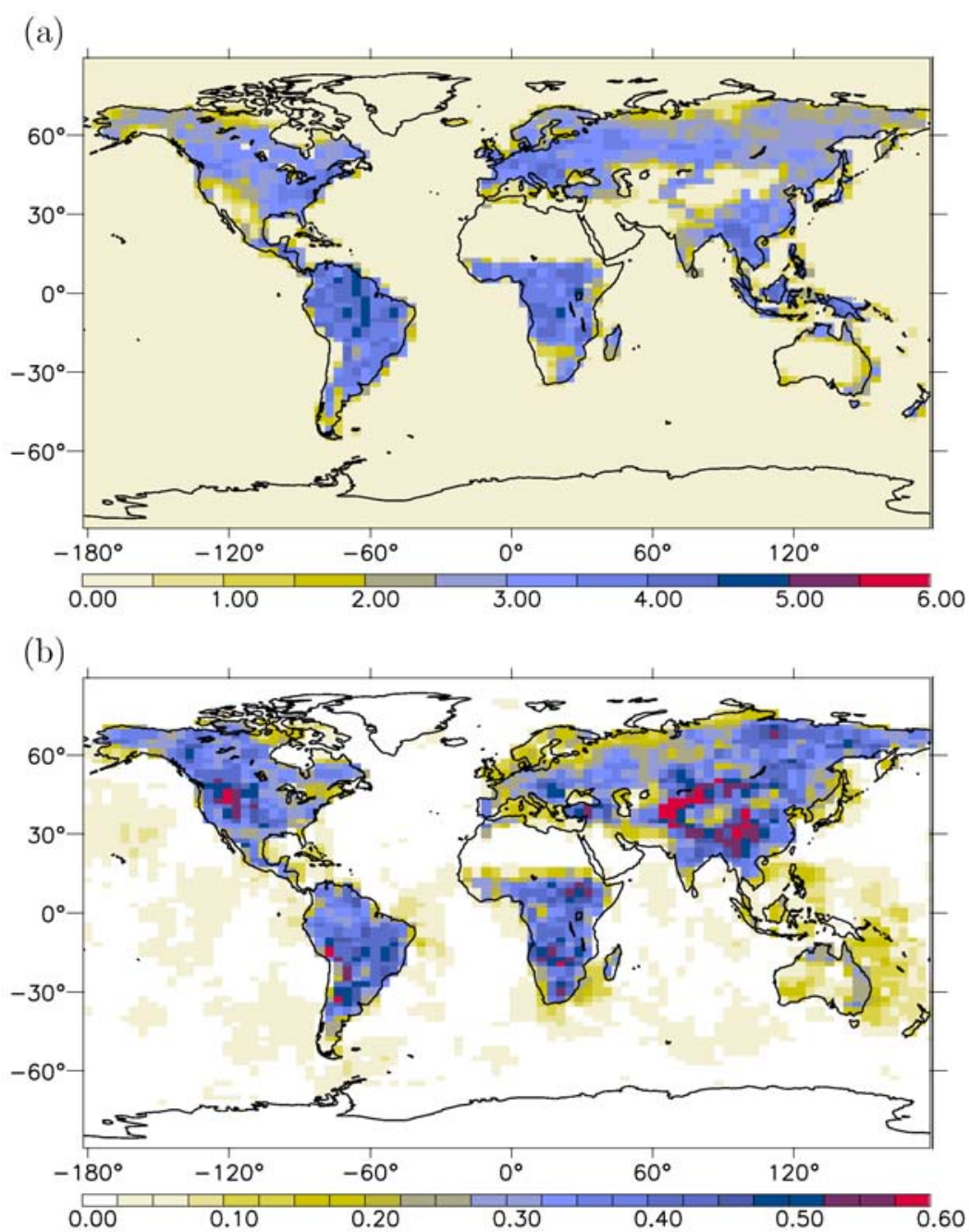

Figure 2. (a) The standard deviation $\sigma_{\mathrm{b}}$ of the errors of the prior fluxes, in $\mathrm{gC} \cdot \mathrm{m}^{-2}$ per day. These statistics correspond to an ensemble of weekly flux errors throughout the year, knowing that the flux error varies in time. (b) The expected uncertainty reduction provided by GOSAT for the estimation of eight-day-mean $\mathrm{CO}_{2}$ surface fluxes. The reduction is defined as $\left(1-\sigma_{\mathrm{a}} / \sigma_{\mathrm{b}}\right)$, with $\sigma_{\mathrm{a}}$ the posterior error standard deviation.

fluxes amounts to about $4.5 \mathrm{GtC}$. Ocean error statistics are more arbitrary and the following parameters have been chosen: (i) temporal correlations decay exponentially with a length of one month; unlike land, daytime and night-time flux errors are fully correlated; (ii) spatial correlations follow an e-folding length of $1000 \mathrm{~km}$, (iii) standard deviations are set to $0.1 \mathrm{gC} \mathrm{m}^{-2}$ day $^{-1}$. With this set-up, the ocean uncertainty amounts to about $0.5 \mathrm{GtC}$ per year. Land and ocean flux errors are not correlated. This configuration expresses the current uncertainty in the numerical models of the global carbon cycle in a simple, but realistic manner. However, it is somewhat subjective and the absolute values of Figures 2 and 3 should be interpreted with caution.

[14] The uncertainty of the inferred fluxes can be rigorously computed from the theory, based on the uncertainty of the prior fluxes, on the uncertainty of the observations and on the uncertainty of the transport model. For large-dimension problems, this is difficult to achieve in practice. Chevallier et al. [2007] have introduced a Monte Carlo approach to address this issue. Posterior error statistics are reconstructed from an ensemble of inversions using synthetic data as input.
When the ensemble of prior fluxes and the ensemble of observations follow their respective assigned error statistics, the ensemble of posterior fluxes consistently follows the

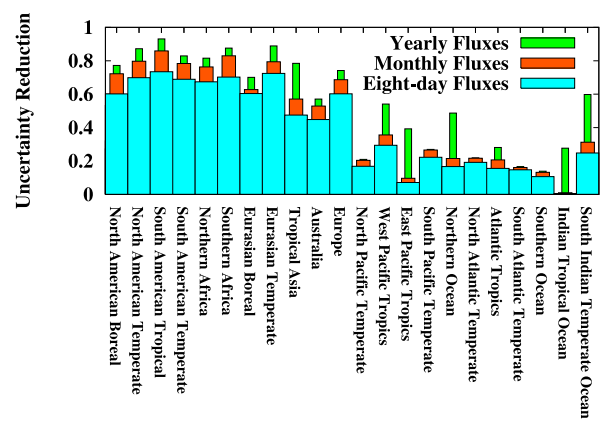

Figure 3. Expected uncertainty reduction provided by GOSAT for the estimation of $\mathrm{CO}_{2}$ surface fluxes in the 22 TransCom-3 regions. Results for weekly, monthly and annual fluxes are shown. As in Figure 2, the error reduction is defined as $\left(1-\sigma_{\mathrm{a}} / \sigma_{\mathrm{b}}\right)$, with $\sigma_{\mathrm{a}}$ the posterior error standard deviation and $\sigma_{\mathrm{b}}$ the prior error standard deviation. 
theoretical statistics of the posterior errors. This feature is exploited here with six one-year inversions of 8-day fluxes for each set-up. Doing that, the method gathers an ensemble of fluxes which is large enough to provide stable statistics for the quantities shown in the following (i.e. the results hardly change when any year among the six is removed from the statistics).

\section{Results}

[15] The global map of the fractional uncertainty reduction of Figure $2 \mathrm{~b}$ quantifies the knowledge brought by GOSAT on the $\mathrm{CO}_{2}$ weekly surface fluxes compared to the accuracy of the global models of the carbon cycle. This quantity is defined as one minus the ratio of the posterior error standard deviation to the prior error standard deviations. A value of zero indicates that the observations have not provided any information to the prior. A value of one would be reached if the observations gave a perfect knowledge about the weekly fluxes. The impact of GOSAT results from the combination of specified prior errors, observation density and transport characteristics. It is mostly located over land, where most of the prior uncertainty lies. It is about $30 \%$ for terrestrial vegetated areas, with values larger than $60 \%$ at places. It is less than $10 \%$ over ocean points. By comparison, our application of the inversion scheme (with also 30 iterations) to the current $\mathrm{CO}_{2}$ concentration monitoring network suggests reductions for grid-point weekly fluxes smaller than $10 \%$ over most areas and up to $30 \%$ only in the vicinity of the stations (not shown). Figure $2 \mathrm{~b}$ shares some similarity with the corresponding figure of Chevallier et al. [2007, Figure 2a] for OCO, with the main differences caused by the revised version of the prior error statistics: (i) the use of the ORCHIDEE hererotrophic respiration fluxes rather than those of a less sophisticated model improves the results at high latitudes; (ii) smaller prior errors over the oceans reduce the impact of the satellite over water; (iii) the introduction of temporal error correlations in this study induce a larger impact over land.

[16] Spatial and temporal averaging may provide even more accurate flux products. Figure 3 shows that the reduction rises to $50-80 \%$ for terrestrial fluxes aggregated at the scale of sub-continental regions, like those of the Atmospheric Tracer Transport Model Intercomparison Project (TransCom3) [Gurney et al., 2002]. As an example, for the TransCom3 'Europe' region, the flux error is theoretically reduced from $1 \mathrm{GtC}$ per year (model uncertainty) to $0.3 \mathrm{GtC}$ per year. For fluxes at the scale of TransCom3 ocean basins, the improvements usually reach about $20 \%$. Aggregating in time up to the monthly or the annual scale brings little improvement over land, likely because of the large temporal correlations of the errors of the posterior fluxes (Figure 3). Over ocean, significant improvements are seen for annual fluxes, with values up to $60 \%$.

\section{Conclusion}

[17] Monitoring $\mathrm{CO}_{2}$ from space is of primary importance to understand and to model the fate of the carbon emitted by human activities. Such approach would complement the accurate surface measurements that are irregularly distributed over the globe. GOSAT is the first instrument conceived to fulfill this objective and to reach orbit. The analysis of this wealth of data will be a topic for active research within the next years. Before the first products are released, this paper evaluates the forthcoming contribution of GOSAT to our knowledge of the $\mathrm{CO}_{2}$ surface fluxes, as contained in numerical models of the global carbon cycle. This letter does not demonstrate the value added to the existing surface network, nor to some specific regional inventory studies (even though the numerical simulations made with the flux inversion scheme used here suggest a larger impact of GOSAT at continental scale than the surface network). The estimate of the uncertainty reduction is relative to the modelling of the various errors in the optimality system: the statistical characteristics of the prior errors and of the observation errors. Our results indicate that GOSAT is likely to provide information about the surface fluxes that is rather similar to what the OCO instrument would have given had it reached orbit in February 2009. OCO would have provided an additional wealth of data (of possibly even higher accuracy than GOSAT) that would have further constrained the inversion problem. The operation of the two instruments in parallel would also have given precious insight about the errors of each other's products.

[18] Our observation system simulation experiments assume a consistent optimality system where all error budgets are accurately known. The application on real data will deviate from this ideal case. Residual biases are the most critical issue. They may hamper and even impede the exploitation of the data in terms of surface fluxes. The quality of the validation of the GOSAT $\mathrm{CO}_{2}$ concentration products will be critical to make the data useful for flux inversion and will determine the reliability of the theoretical diagnostics like those presented here.

[19] Acknowledgments. GOSAT is a joint effort promoted by the Japan Aerospace Exploration Agency (JAXA), the National Institute for Environmental Studies (NIES) and the Ministry of the Environment (MOE) in Japan. The computations reported here have been performed on the computers of the Centre de Calcul Recherche et Technologie (CCRT). This study was co-funded by the European Commission under the EU Seventh Research Framework Programme (grant agreement 218793, MACC). The authors wish to thank D. Crisp, C. E. Miller (NASA), I. G. Enting (U. of Melbourne) and an anonymous reviewer for constructive comments.

\section{References}

Bréon, F. M., and N. Henriot (2006), Spaceborne observations of ocean glint reflectance and modeling of wave slope distributions, J. Geophys. Res., 111, C06005, doi:10.1029/2005JC003343.

Chevallier, F. (2007), Impact of correlated observation errors on inverted $\mathrm{CO}_{2}$ surface fluxes from OCO measurements, Geophys. Res. Lett., 34, L24804, doi:10.1029/2007GL030463.

Chevallier, F., R. J. Engelen, and P. Peylin (2005a), The contribution of AIRS data to the estimation of $\mathrm{CO}_{2}$ sources and sinks, Geophys. Res. Lett., 32, L23801, doi:10.1029/2005GL024229.

Chevallier, F., M. Fisher, P. Peylin, S. Serrar, P. Bousquet, F.-M. Bréon, A. Chédin, and P. Ciais (2005b), Inferring $\mathrm{CO}_{2}$ sources and sinks from satellite observations: Method and application to TOVS data, J. Geophys. Res., 110, D24309, doi:10.1029/2005JD006390.

Chevallier, F., N. Viovy, M. Reichstein, and P. Ciais (2006), On the assignment of prior errors in Bayesian inversions of $\mathrm{CO}_{2}$ surface fluxes, Geophys. Res. Lett., 33, L13802, doi:10.1029/2006GL026496.

Chevallier, F., F.-M. Bréon, and P. J. Rayner (2007), The contribution of the Orbiting Carbon Observatory to the estimation of $\mathrm{CO}_{2}$ sources and sinks: Theoretical study in a variational data assimilation framework, J. Geophys. Res., 112, D09307, doi:10.1029/2006JD007375.

Connor, B. J., H. Boesch, G. Toon, B. Sen, C. Miller, and D. Crisp (2008), Orbiting Carbon Observatory: Inverse method and prospective error analysis, J. Geophys. Res., 113, D05305, doi:10.1029/2006JD008336. 
Crisp, D., et al. (2004), The Orbiting Carbon Observatory (OCO) mission, Adv. Space Res., 34(4), 700-709, doi:10.1016/j.asr.2003.08.062.

Eguchi, N., and T. Yokota (2008), Investigation of clear-sky occurrence rate estimated from CALIOP and MODIS observations, Geophys. Res. Lett. 35, L23816, doi:10.1029/2008GL035897.

Fisher, M., and P. Courtier (1995), Estimating the covariance matrices of analysis and forecast error in variational data assimilation, Tech. Memo. 220, 26 pp., Eur. Cent. for Medium-Range Weather Forecast, Reading, U. K.

Gurney, K. R., et al. (2002), Towards robust regional estimates of $\mathrm{CO}_{2}$ sources and sinks using atmospheric transport models, Nature, 415, 626-630, doi:10.1038/415626a.

Hourdin, F., et al. (2006), The LMDZ4 general circulation model: Climate performance and sensitivity to parametrized physics with emphasis on tropical convection, Clim. Dyn., 27, 787-813, doi:10.1007/s00382 006-0158-0.

Krinner, G., N. Viovy, N. deNoblet-Ducoudré, J. Ogée, J. Polcher, P. Friedlingstein, P. Ciais, S. Sitch, and I. C. Prentice (2005), A dynamic global vegetation model for studies of the coupled atmospherebiosphere system, Global Biogeochem. Cycles, 19, GB1015, doi:10.1029/ 2003GB002199.

Lüthi, D., et al. (2008), High-resolution carbon dioxide concentration record 650,000-800,000 years before present, Nature, 453, 379-382, doi:10.1038/nature06949.

Maksyutov, S., N. Kadygrov, Y. Nakatsuka, P. K. Patra, T. Nakazawa, T. Yokota, and G. Inoue (2008), Projected impact of the GOSAT observations in regional $\mathrm{CO}_{2}$ fluxes estimations as a function of total retrieval error, J. Remote Sens. Soc. Jpn., 28(2), 190-197.

Ota, Y., Y. Yoshida, and T. Yokota (2008), Study of retrieving column amount of carbon dioxide from satellite-based near-infrared observation of solar scattered light in clear sky condition-Error estimation and optimization of vertical pressure grid, J. Remote Sens. Soc. Jpn., 28(2), $152-160$

Rayner, P. J., and D. M. O'Brien (2001), The utility of remotely sensed $\mathrm{CO}_{2}$ concentration data in surface source inversions, Geophys. Res. Lett., 28, 175-178, doi:10.1029/2000GL011912.

Yokota, T., H. Oguma, I. Morino, and G. Inoue (2004), A nadir looking SWIR FTS to monitor $\mathrm{CO}_{2}$ column density for Japanese GOSAT project, paper presented at 24th International Symposium on Space Technology and Science, Jpn. Soc. for Aeronaut. and Space Sci., Miyazaki, Japan.

Yokota, T., T. Aoki, N. Eguchi, Y. Ota, Y. Yoshida, S. Oshchepkov, A. Bril, R. Desbiens, and I. Morino (2008), Data retrieval algorithms of the SWIR bands of the TANSO-FTS sensor aboard GOSAT, J. Remote Sens. Soc. Jpn., 28(2), 152-160.

P. Bousquet, F.-M. Bréon, and F. Chevallier, Laboratoire des Sciences du Climat et de 1'Environnement, CEA, UVSQ, IPSL, CNRS, F-91191 Gif-sur-Yvette, France. (frederic.chevallier@1sce.ipsl.fr)

S. Maksyutov, R. Saito, T. Yokota, and Y. Yoshida, National Institute for Environmental Studies, Tsukuba, Ibaraki 305-8506, Japan. 